\title{
Longitudinal Associations Between Bullying and Children's Preference for Television Violence
}

\author{
Panayiotis Stavrinides*, Andriana Tsivitanou, Militsa Nikiforou, Veronica Hawa and \\ Vasiliki Tsolia
}

\section{Department of Psychology, University of Cyprus, Cyprus}

\begin{abstract}
The aim of this study was to examine the longitudinal associations between bullying and preference for violent television programs. A sixth-month, two time-point longitudinal design was used in order to identify the direction of the relation between bullying and preference for violent television programs. The participants were 417 sixth grade students of elementary schools in Cyprus. They completed the bullying subscale of the Revised Bullying and Victimization Questionnaire (BVQ-R) and the Preference for Television Violence Questionnaire (PTVQ). The findings of this study suggested a reciprocal relation between preference for violent TV programs and bullying. Specifically, bullying at Time1 positively predicted an increase in violent TV programs preference at Time 2 . Similarly, preference for TV violence at Time1 positively predicted bullying at Time 2 . We conclude that prior involvement in bullying may function as a risk factor for more future preference for violent programs on television and at the same time children who already prefer violent programs are more likely to manifest bullying in the future.
\end{abstract}

Keywords: Bullying, television violence, longitudinal study.

Bullying among children is an international, widespread phenomenon which has been under investigation during the past few decades (Olweus, 1993). Despite cultural differences, many of the predominant features of bullying are similar across different countries (Smith et al., 1999). Farrington (1993) claims that bullying is a common phenomenon at schools, taking place at all grade levels and mostly beyond elementary school.

Children are bullied when they are repeatedly exposed to negative actions from one or more students. Bullying also involves a significant imbalance of power that is often called an asymmetric power relationship (Farrington, 1993; Olweus, 1993) As a result, victims become incapable defending themselves. It involves a series of negative actions that intentionally inflict, or attempt to inflict physical or psychological harm or discomfort. Verbal forms of bullying include threats, teasing, name-calling, and taunting while hitting, pushing, and kicking are direct and physical forms. Also, bullying can manifest as an intention to exclude children from their peer groups (Olweus, 1993).

Children involved in bullying incidents usually assume distinct roles. Such roles include the victim, the bully, the reinforcer of the bully, the assistant of the bully, the defender of the victim and the outsider (Salmivalli, Lagerspetz, Björkqvist, Osterman \&

\footnotetext{
*Address correspondence to this author at the Department of Psychology, University of Cyprus, 1678, 20537, Nicosia, Cyprus; Tel: ++35722892073; Fax: ++35722895075; E-mail: stavrini@ucy.ac.cy
}

Kaukiainen, 1998). Other authors however, classify three major profiles; bullies, victim, and bully/victims (Georgiou \& Stavrinides, 2008; Graham \& Juvonen, 2001).

Recently, bullying has been labeled as a health related problem because it is associated with a number of adjustment problems, including poor mental health and long-term violent behavior (Juvonen, Graham, \& Schuster, 2003). Despite the severity that is implied by defining bullying as a health related problem, the risk factors however are still poorly understood (Zimmerman, Glew, Christakis, \& Katon, 2005).

Over the past two decades a number of researchers have placed their efforts in documenting why bullying occurs (Olweus, 1993; Carney \& Merrell, 2001). In summarizing some of the findings of these studies, bullying appears to be related to aggressive parenting practices, inconsistent parenting, strict parental punishments or strategies, minimal supervision, poor problem-solving ability, and high levels of family conflict (Griffin \& Cross, 2004).

\section{Exposure to Media Violence and Childhood Aggression: Theoretical Models}

The effects of television exposure in children are a growing concern. Numerous studies have repeatedly shown associations between viewing violent television programs and physical aggression among children. Over the past three decades a significant number of studies have investigated whether the two are causally related (Bushman \& Huesmann, 2001; Huesmann, Lagerspetz \& Eron, 1984). 
Some authors claim that exposure to TV violence is indeed a risk-factor for the development of aggressive behaviour in children (Huesmann, Moise, Podolski \& Eron, 2003). Other empirical studies that investigated media have demonstrated that one of the ways in which children learn to be aggressive is through the quality and the quantity of the programs they watch on television. (Kuntsche, Pickett, Overpeck, Graig, Boyce \& Gaspar, 2006; Wartella \& Reeves, 1985). Zimmerman et al., (2005) claim that bullying - along with other types of aggression, obesity, and lack of attention - might result from the negative consequences of excessive television viewing.

Several models have been proposed in explaining why learning is so critical in acquiring aggressive and violent tendencies. Social learning theory for example, suggests that people learn through observation, imitation, and modeling. Since the mechanism of modeling explains why in very early stages children learn a vast number of behaviours, it is also assumed that aggressive and violent attitudes are developed through modeling. Therefore when children are repeatedly exposed to positively reinforced aggressive models they are likely to adopt a more aggressive behavior in the future (Bandura, 1986).

Priming effects theory is another model aiming to explain how violent and aggressive behaviour can be learned. According to this theory, media impacts are immediate, transitory and short-term. It suggests that while people watch violent scenes on TV, other related aggressive thoughts and even behaviors are "primed" (Berkowitz, 1984).

According to Huesmann's processing model aggressive behaviors are designed and programmed in a script that is established during childhood. Aggression is developed through an observational or enactive learning process in which aggressive scripts are acquired and maintained. These scripts are stored in memory and they control future social behaviors and problem solving. In this way, violent scenes are encoded in the memory of children and influence their later attitudes toward violence. Moreover, observed violence not only provides scripts for future behavior but it can also trigger the recall of existing aggressive scripts (Huesmann, 1987).

\section{Empirical Studies}

Linder \& Gentile (2009) examined the effects of media violence considering not only the physical - direct - forms but also the non-physical - indirect forms of aggression. The results of this study revealed strong associations between exposure to TV violence (direct and indirect) and child aggression. In the same line, Coyne, Archer and Eslea (2004) also found that indirect media aggression can have an impact on subsequent actual aggression in childhood. In the United States, the Surgeon General's Scientific Advisory Committee on Television and Social Behavior report (1972) and a follow-up report in 1982 by the National Institute of Mental Health identified an array of major effects of television violence: children may become less sensitive to the pain and suffering of others, more fearful of the world around them, and more likely to behave in an aggressive or harmful way.

In a recent study, Fanti, Vamman, Henrich and Avraamides (2009) found that repeated exposure to media violence reduces the psychological impact of media violence in the short term and creates desensitization to media violence. As a result, viewers tend to feel less sympathetic toward victims of violence.

In a study of the long-term effects of television violence on aggressive and criminal behavior was found a longitudinal relationship between habitual childhood exposure to television violence and adult crime. Television viewing especially encourages some people to become violent and immoral (Huesmann et al., 1984). Antisocial acts such as murders, rapes, bullying and thefts are reinforced by television (Charlton, 1998).

In experimental studies, boys and girls exposed to violent behavior on film or TV behave more aggressively immediately afterward. Children who are shown either a violent or nonviolent short film and are observed afterward as they play with each other behave more aggressively toward each other (Bandura, 1986; Josephson, 1987).

Kuntsche et al. (2006), found that in eight countries across Europe and North America, between adolescents, television viewing was strongly associated with verbal form of bullying such as calling names and spreading rumors. The association however between television viewing and physical forms of bullying such as kicking and pushing varied across countries.

Longitudinal studies on children's exposure to TV violence and aggressive behavior during adulthood, show that childhood exposure to media violence predicts young adult aggressive behavior for both 
males and females. Physical aggression was more likely in both males and females whereas indirect aggression was strongly associated only in females. Also, more childhood exposure to TV violence shows greater childhood identification with same-sex aggressive TV characters. In turn, this identification predicted later aggression during the early years of adulthood. (Eron, Lefkowitz, Huesmann \& Walder, 1972; Huesmann et al., 2003).

Over the past several decades a body of literature and research strongly supported the idea that exposure to media violence contributes to the development of aggressive behavior (Huesmann et al.,1984; Comstock \& Strasburger, 1990). Even though the relation between aggressive behavior and television habits has been demonstrated in many survey studies; the causal nature of this relation is yet not clear. Does violent programming cause aggressive behavior or do children who are already aggressive choose to watch violent programming? (Comstock \& Strasburger, 1990; Eron et al., 1972; Huesmann, 1982; Huesmann et al., 1984).

\section{The Present Study}

Even though a great emphasis was placed in the past in the relation between media violence and aggressive behavior, only a few studies investigated the link between exposure to media violence with bullying (e.g Kuntsche, 2004). More importantly, the present study aims to examine the direction of the relation between bullying and children's preference for TV violence. Specifically, we examine if there is a oneway relation between the two variables or a bidirectional relation as it is proposed in most of the past aggression-tv violence literature. Therefore, our goal was to identify whether (a) bullying is the reason why children view more violent programs on television, (b) preexisting viewing of media violence causes bullying, and (c) the relation between these two variables is reciprocal.

\section{METHOD}

\section{Participants}

The participants of the present study were 417 (217 boys and 209 girls) students attending the sixth grade of elementary school (mean age $=11.5$ years, S.D. = .35 years). They were selected from fifteen public elementary schools in Cyprus (thirteen public schools and two private schools). The socioeconomic data of the participants show that $15 \%$ of the sample comes from low socioeconomic status families, $74 \%$ from middle socioeconomic status, while $11 \%$ from high socioeconomic status reflecting the general socioeconomic distribution of Cypriot families.

\section{Instruments}

\section{Revised Bullying and Victimization Questionnaire - $B V Q-R$}

For the purpose of the present study we used only the bullying subscale of this instrument. The subscale consists of nine items based on the original questionnaire initially constructed by Olweus (1996) and it has been recently used in a number of studies in Cyprus after its adaptation in Greek language (Georgiou \& Stavrinides, 2008; Georgiou, 2008; Kyriakides et al., 2006). The subscale yields one companioning reflecting the dimension of bullying. Items from the subscale include statements such as "other children complain that I hit them", "I want other children to do as I say", "other children are afraid of me". Children responded to each item on a 5-point Likert-type scale. Cronbach alpha reliabilities for the bullying factor were .88 for Time 1 and .83 for Time 2 .

\section{Preference for Television Violence Questionnaire (PTVQ)}

The PTVQ was constructed by our research group for the purpose of the present study. The instrument consists of 5 items that measure preference for TV violence. The items from the scale include the following statements: "How often do you watch movies that contain violent scenes?", "How many times have you seen in television somebody hitting violently someone else?", "How many times have you seen a killing scene in television?", "To what extent do you like a movie that contains scenes of violence?", "To what extent do you prefer watching violent movies than other kinds of programs?". Children responded to each item on 5point Likert-type scale. Cronbach alpha reliabilities for the preference for TV violence factor were .89 for Time 1 and .88 for Time 2.

\section{Procedure}

Both instruments were administered to the sample in two points in time, Time 1 and Time 2, with six months interval between the two data collection phases. The children that participated in our study were informed about the purpose of the study and were asked to complete the instruments on a voluntary basis. Issues of anonymity and personal data protection were explicitly stressed by the researchers. 
Table 1: Means and Standard Deviations (Scale 1 - 5) for the Composite Scores on the Factors of Bullying and Preference for Television Violence

\begin{tabular}{|c|c|c|c|c|}
\hline \multirow{2}{*}{ Construct } & \multicolumn{2}{|c|}{ Time1 } & \multicolumn{2}{|c|}{ Time2 } \\
\cline { 2 - 5 } & Mean & SD & 1.39 & .49 \\
\hline \hline Bullying & 1.57 & .71 & 2.57 & 1.05 \\
\hline Preference for television violence & 2.64 & 1.09 & \multicolumn{2}{|c|}{ SD } \\
\hline
\end{tabular}

The order of appearance of the two instruments was randomized in order to avoid any possible bias.

\section{RESULTS}

Exploratory Factor Analysis (EFA) was computed for both the Bullying Subscale and Preference for Television Violence Questionnaire. The results of this analysis show that the Bullying subscale extracts a single factor which explains $50 \%$ of the total variance at Time 1 and $42 \%$ at Time 2. In both phases, the items loaded as predicted onto one single factor representing bullying (all factor loadings $>$.51). Similarly, factor analysis on the Preference for Television Violence Questionnaire yielded a solution which explains $70 \%$ of the variance of the data at Time 1 and $69 \%$ at Time 2 . In both occasions, the items loaded as predicted onto one single factor representing preference for TV violence (all factors loadings > .64).

Since the factors of Bullying and Preference for TV violence showed strong internal consistencies, we computed a composite variable for each construct, which represents the mean score for each case item that compose each factor. Table 1 shows the means and standard deviations for each composite construct.

Before examining the predictive significance of the bullying and exposure to TV violence factors we computed bivariate correlations between all scores at Time 1 and Time 2 in order to identify associations among bullying and exposure to TV violence. The results showed statistically significant positive correlations between bullying and children's' preference for television violence at Time 1 and Time2. Table 2 shows details of these correlations.

The next step in the data analysis was to compute a hierarchical regression analysis in order to investigate whether bullying at Time 1 predicts an increase in exposure to TV violence at Time 2, controlling for the variance explained by preference for TV violence at Time 1. We also examined if exposure to TV violence at Time 1 predicts an increase in bullying at Time 2 ,

Table 2: Correlation Coefficients Between Bullying and Preference for Television Violence at Time 1 and Time 2

\begin{tabular}{|c|c|c|c|c|}
\hline 1. Bullying $T 1$ & - & $.32^{* *}$ & $.44^{* *}$ & $.28^{\star *}$ \\
\hline 3. Bullying T2 & & & & $.42^{* *}$ \\
\hline 4. Preference for TV violence T2 & & & & - \\
\hline
\end{tabular}

${ }^{* *} \mathrm{p}<.01$.

Table 3: Hierarchical Regression Analysis Predicting Preference for Television Violence at Time 2 from Time 1 Measures

\begin{tabular}{|c|c|c|}
\hline & \multicolumn{2}{|c|}{ Dependent Measures Preference for television violence } \\
\hline \hline Step 1 & $\beta$ & $\mathrm{R}^{2}$ \\
\hline Preference for television violence & $.27^{* *}$ & .12 \\
\hline Step 2 & $\beta$ & $\Delta \mathrm{R}^{2}$ \\
\hline Bullying & $.08^{*}$ & .02 \\
\hline
\end{tabular}

${ }^{*} p<0.05,{ }^{* *} p<0.01$

note: preference for TV violence at time 1 is controlled for in step 2. 
Table 4: Hierarchical Regression Analysis Predicting Bullying at Time 2 from Time 1 Measures

\begin{tabular}{|c|c|c|}
\hline & \multicolumn{2}{|c|}{ Dependent Measures Bullying } \\
\hline \hline Step 1 & $\beta$ & $\mathrm{R}^{2}$ \\
\hline Bullying & $.43^{\star *}$ & .19 \\
\hline Step 2 & $\beta$ & $\Delta \mathrm{R}^{2}$ \\
\hline Preference for television violence & $.18^{* *}$ & .03 \\
\hline
\end{tabular}

${ }^{* *} p<0.01$

note: bullying at time 1 is controlled for in step 2

controlling for the variance explained by bullying at Time 1.

The results show that bullying at Time 1 positively predicted the exposure to TV violence at Time 2 (see Table 3) even after controlling for the variance explained by preference for violent TV programs at T1.

Similarly, we found that exposure to TV violence at Time 1 positively predicted bullying at Time 2 (see Table 4) after controlling for the variance explained by bullying at $\mathrm{T} 1$.

In order to provide further validation to our results, we attempted to confirm the bidirectional model of the relation between the two constructs (bullying and exposure to TV violence) through Structural Equation Modeling. This statistical technique allows for theory testing upon latent constructs. The hypothesized interrelations of the two constructs at the two Times of our study appear at Figure 1. The ability of the structure to fit the data was tested by means of EQS software (Bentler, 2004) and the modeling procedure followed the currently accepted statistical practice along with paradigms from other related studies (e.g. Georgiou, 2008). In our study we computed three fit indices: The comparative fit index (CFI), the root meansquare error of approximation (RMSEA), and the chisquare to its degrees of freedom ratio $\left(X^{2} / d f\right)$. As Marcoulides and Schumacker (1996) point out, a tested model is confirmed when the CFI is close to 1.0 , the RMSEA values close to zero, and the $x^{2} /$ df less than 2.0. The fit indices of the tested model satisfy adequately these criteria. The only modification we employed on the initial tested model was the correlation coefficients between bullying and exposure to TV violence at Time 1 and Time 2. $(\mathrm{CFI}=.98$; RMSEA $\left.=.03[\mathrm{Cl}=.02-.04] ; \mathrm{X}^{2} / \mathrm{df}=1.84\right)$.

Two alternative models were also tested. Both models represent the unidirectional interpretation of the relation between bullying and exposure to TV violence. The first alternative model reflects bullying at Time 1

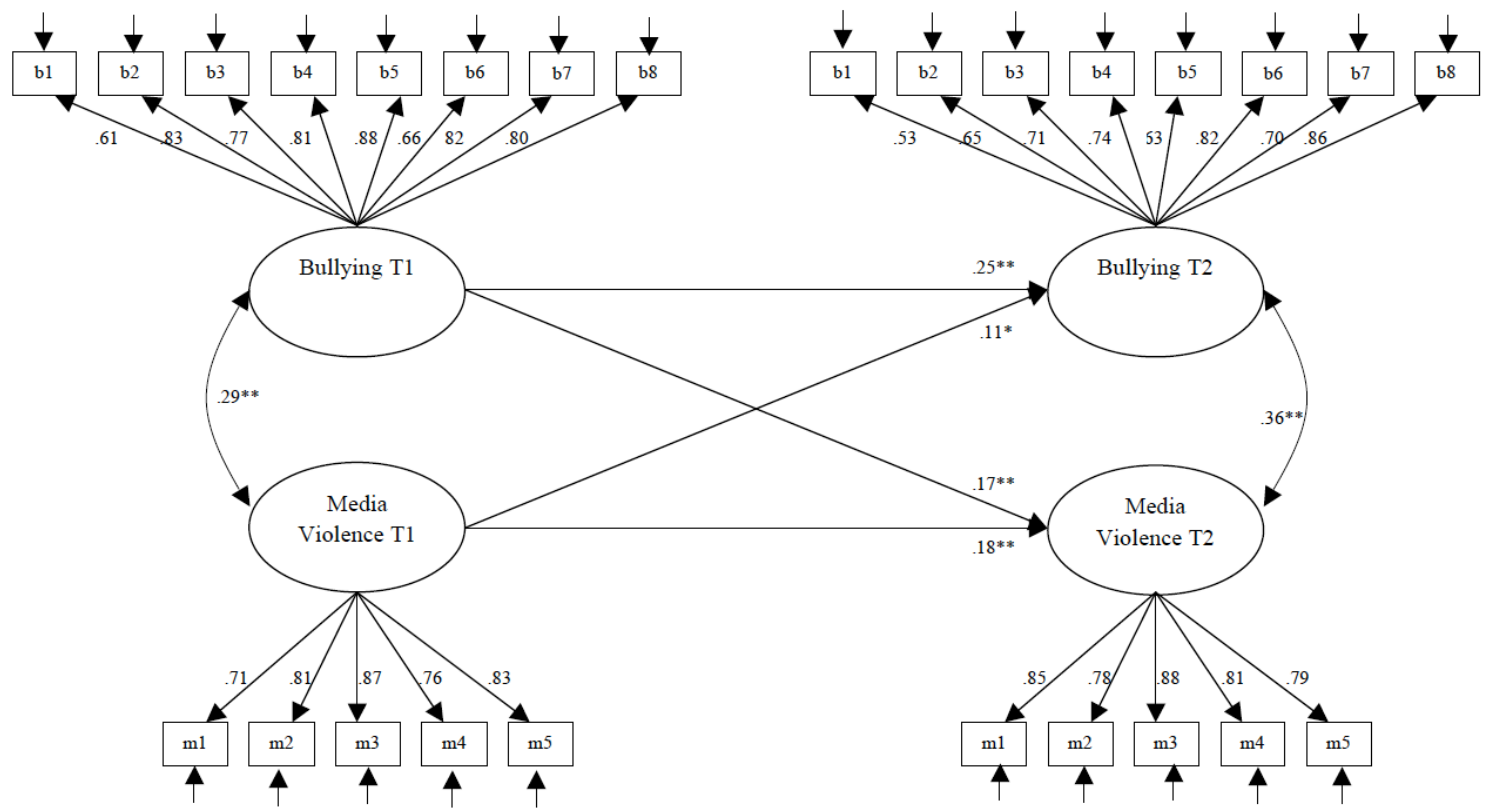

Figure 1: The tested model showing the longitudinal associations between bullying and preference for television violence. 
predicting an increase in the exposure of TV violence at Time 2 while no opposite effects are computed (i.e. media violence at Time 1 to bullying at Time 2). The second model reflects exposure to TV violence at Time 1 predicting an increase in bullying at Time 2 while no opposite effects are computer neither (i.e. bullying at Time 1 to media violence at Time 2). Both models however did not show adequate fit indices (for both alternative models $\mathrm{CFI}<.90$, RMSEA $>.10, \mathrm{X}^{2} / \mathrm{df}>2.0$ )

\section{DISCUSSION}

Earlier studies focused mostly in the relation between media violence and aggressive behavior, not specifically on bullying which remains an important manifestation of childhood aggression (Griffin \& Gross, 2004). Along these lines, several longitudinal studies have already claimed that there is a bidirectional relation between exposure to media violence and aggressive behavior. As some authors argue, violence viewing engenders aggression, and aggression engenders violence viewing. (Huesmann et al., 1984).

In line with Kuntsche et al., (2006) our study shows a strong association between exposure to media violence and a specific form of childhood aggression such as bullying. More importantly, our findings indicate a bidirectional relation between bullying and exposure to media violence. Our model of interpretation describes a "vicious cycle" of potential causes and consequences in the relationship between bullying and exposure to media violence (Huesmann, et al., 1984). It is important to note that the alternative-unidirectional models that were tested did not show adequate statistical fit. This might be explained at least partly because of the reciprocal nature of the relationship between bullying and preference for violent content television programs.

Researchers, practitioners, and even parents often reflect on such issues in terms of unidirectional effects; children become involved in bullying because of what they watch on television, or, they watch violent programs because it fits their already developed violent temperament. Our study, while it does not completely reject such arguments, it also shows the circular nature of the relation between bullying and exposure to violent programs on television. Our interpretation of this relation is a dynamic way of understanding psychological and behavioural manifestations such as bullying and its relation to choices of socialization such as the quality and the content of the programs viewed by children.
In conclusion, we argue that bullying and the exposure to programs of violent content are closely interrelated. Children with limited opportunities for healthy socialization choices along with a lack of parental guidance or monitoring may find themselves easier in choosing violent television programs as a means of socialization. That in turn becomes a risk factor for future involvement in bullying or generally aggressive incidents. At the same time, however, the opposite direction of effects might also be true. Children who already get in involved in bullying incidents may find themselves more easily in choosing violent programs in television as a substitute of the gratification they feel from imposing themselves upon other children.

\section{Limitations and Contribution of the Present Study}

The present study focuses only on the relationship between two constructs; bullying and exposure to television programs with violent content. Despite the significance of this relationship it would be problematic to interpret why children engage in bullying or why children choose violent programs only within the narrow scope of this study. Other important factors such as the role parents, personality characteristics, and social/emotional aspects of children may play an important role in both issues we investigated in our study.

Nonetheless, this study provides further empirical evidence to support the argument that there is indeed a true relation between involvement in bullying and exposure to media violence. Moreover, the design of our study allows us to argue of the reciprocal nature of this relationship providing evidence why bullying and media violence can be seen as causal agents and consequences.

\section{REFERENCES}

Bandura, A. (1986). Social foundations of thought and action: a social cognitive theory. Englewood Cliffs: Prentice Hall.

Bentler, P.M. (2004). EQS Structural Equation Program Manual. Encino, CA: Multivariate Software,

Berkowitz, L. (1984). Some effects of thoughts on anti-social and prosocial influences of media events: A cognitive neoassociationistic analysis. Psychological Bulletin, 95(3), 410-27.

http://dx.doi.org/10.1037/0033-2909.95.3.410

Bushman, B. J., \& Huesmann, L. R. (2001). Effects of televised violence on aggression. In D. G. Singer,\&J. L. Singer (Eds.), Handbook of children and the media (pp. 223-254). Thousand Oaks, CA: Sage.

Carney, A. G., \& Merrell, K. W. (2001). Bullying in schools: Perspective on understanding and preventing an international problem. School Psychology International, 22(3), 364-382.

http://dx.doi.org/10.1177/0143034301223011 
Charlton, T. (1998). Reproaching television for violence in society: passing the buck? Interim results from a naturalistic study in St Helena, South Atlantic. Journal of Clinical Forensic Medicine, 5, 169-171.

http://dx.doi.org/10.1016/S1353-1131(98)90128-6

Comstock, G., \& Strasburger, V. C., (1990). Deceptive appearances: Television Violence and Aggressive Behavior. Journal of Adolescent Health Care, 11, 31-44. http://dx.doi.org/10.1016/0197-0070(90)90127-N

Coyen, S. M., Archer, J., \& Elsea, M. (2004). Cruel intentions on television and in real life: Can viewing indirect aggression increase viewers' subsequent indirect aggression? Experimental Child Psychology, 88, 234-253. http://dx.doi.org/10.1016/j.jecp.2004.03.001

Eron, L. D., Lefkowitz, M. M., Huesmann, L. R., \& Walder, L. O. (1972). Does television violence cause aggression? American Psychologist, 253-263. http://dx.doi.org/10.1037/h0033721

Fanti, K. A., Vanman, E., Henrich, C. C., \& Avraamides, M.A. (2009). Desensitization to media violence over a short period of time. Aggressive Behavior, 35, 179-187.

http://dx.doi.org/10.1002/ab.20295

Farrington, D. (1993). Understanding and Preventing Bullying. In M. Tonry (Ed.), Crime and Justice: A Review of Research, Vol. 17. Chicago and London: University of Chicago Press.

Georgiou, St. (2008). Bullying and victimization at school: the role of mothers. British Journal of Educational Psychology, 78, 109125. http://dx.doi.org/10.1348/000709907X204363

Georgiou, S. N., \& Stavrinides, P. (2008). Bullies, Victims and BullyVictims: Psychosocial Profiles and Attribution Styles. School Psychology International 29, 574-589. http://dx.doi.org/10.1177/0143034308099202

Graham, S. \& Juvonen, J. (2001). An Attributional Approach to Peer Victimization, in S. Graham and J. Juvonen (Eds) Peer Harassment in School: The Plight of the Vulnerable and Victimized, pp. 49-72. New York: Guilford Press.

Griffin, R. S., \& Gross, A. M. (2004). Childhood bullying: Current empirical findings and future directions for research. Aggression and Violent Behavior 9, 379-400. http://dx.doi.org/10.1016/S1359-1789(03)00033-8

Huesmann, L. R. (1982). Television violence and aggressive behavior. In D. Pearl, L. Bouthilet, \& J. Lazar (Eds.), Television and behavior Ten years of scientific progress and implications for the eighties, (pp. 126-137). Washington, DC: U.S.Government Printing Office.

Huesmann, L. R., Lagerspetz, K., \& Eron, D. L. (1984). Intervening variables in the television violence-aggression relation: evidence from two countries. Developmental Psychology, 20(5), 746-775.

http://dx.doi.org/10.1037/0012-1649.20.5.746

Huesmann, L. R., (1987). An information processing model for the development of aggression. Aggressive Behavior, 14, 13-24. http://dx.doi.org/10.1002/1098-2337(1988)14:1<13::AIDAB2480140104>3.0.CO;2-J

Huesmann, L. R., Moise-Titus, J., Podolski, C. L., \& Eron, L. D. (2003). Longitudinal relations between children's exposure to television violence and their aggressive and violent behavior in young adulthood. Developmental Psychology, 39(2), 201221.

http://dx.doi.org/10.1037/0012-1649.39.2.201
Josephson, W. L. (1987). Television violence and children's aggression: Testing the priming, social script, and disinhibition predictions. Journal of Personality and Social Psychology, 53, 882-890.

http://dx.doi.org/10.1037/0022-3514.53.5.882

Juvonen, J., Graham, S., \& Schuster, M.A. (2003). Bullying among young adolescents: The strong, the weak, and the troubled. Pediatrics, 112, 1231-1237. http://dx.doi.org/10.1542/peds.112.6.1231

Kuntsche, N. E. (2004). Hostility Among Adolescents in Switzerland? Multivariate Relations Between Excessive Media Use and Forms of Violence. Journal of Adolescent Health, 34, 230236.

Kuntsche, N. E., Pickett, W., Overpeck, M., Craig, W., Boyce W., \& Gaspar, M. M. (2006). Television Viewing and Forms of Bullying among Adolescents from Eight Countries. Journal of Adolescent Health, 39, 908-915. http://dx.doi.org/10.1016/j.jadohealth.2006.06.007

Kyriakides, L., Kaloyirou, C., \& Lindsay, G. (2006). An analysis of the revised Olweus bully/victim questionnaire using the Rasch measurement model. British Journal of Educational Psychology, 76, 781-801. http://dx.doi.org/10.1348/000709905X53499

Linder, J.R, \& Gentile, D.A (2009).Is the television rating system valid? Indirect, verbal, and physical aggression in programs viewed by fifth grade girls and associations with behavior. Journal of Applied Developmental Psychology, 30, 286-297. http://dx.doi.org/10.1016/j.appdev.2008.12.013

Marcoulides, G., \& Schumacker, R. (1996). Advanced structural equation modeling: issues and techniques. Hilsdale: Erlbaum.

National Institute of Mental Health (1982). Television and Behavior. Ten years of Scientific Progress and Implications for the Eighties, vol 1. Rockville, MD: U.S. Department of Health and Human Services.

Olweus, D. (1993). Bullying at school. Oxford: Blackwel.

Olweus, D. (1996). The revised Olweus Bully/Victim questionnaire for students. Bergen, Norway: University of Bergen.

Salmivalli, C., Lagerspetz, K., Björkqvist, K., ,Österman, K., \& Kaukiainen A. (1998). Bullying as a group process: Participant roles and their relations to social status within the group. Aggressive Behavior, 22(1), 1-15. http://dx.doi.org/10.1002/(SICI)1098-2337(1996)22:1<1::AIDAB1>3.0.CO;2-T

Smith, P.K, Morita, Y., Junger-Tas, D., Olweus, D., Catalano, R., \& Slee, P. (1999). The nature of school bullying. A crossnational perspective. London: Routledge.

U.S. Surgeon General's Scientific Advisory Committee on Television and Social Behavior. (1972). Television and growing up: The impact of televised violence. Washington, DC.

Wartella, E. \& Reeves, B. (1985). Historical trends in research on children and the media: 1900-1960. Journal of Communication 35(2), 118-33. http://dx.doi.org/10.1111/j.1460-2466.1985.tb02238.x

Zimmerman,F.J., Glew, G.M., Christakis, D.A \& Katon, W. (2005). Early cognitive stimulation, emotional support, and television watching as predictors of subsequent bullying among gradeschool children. Archives of Pediatric Adolescent Medicine, 159, 384-388. http://dx.doi.org/10.1001/archpedi.159.4.384

\section{DOI: http://dx.doi.org/10.6000/1929-4409.2013.02.7}

(C) 2013 Stavrinides et al.; Licensee Lifescience Global.

This is an open access article licensed under the terms of the Creative Commons Attribution Non-Commercial License (http://creativecommons.org/licenses/by-nc/3.0/) which permits unrestricted, non-commercial use, distribution and reproduction in any medium, provided the work is properly cited. 